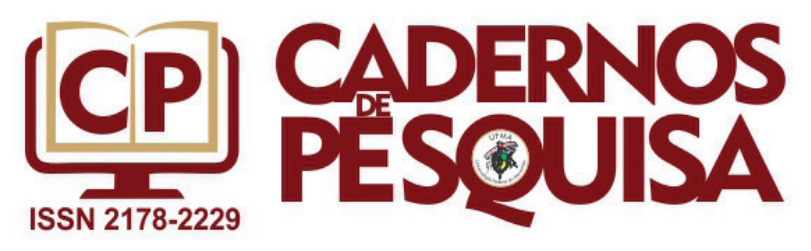

\title{
Os meios e os fins da educação social na sociedade capitalista
}

\author{
The means and purposes of social education in the capitalist \\ society
}

\section{Los medios y los fines de la educación social en la sociedad capitalista}

\author{
Maria Escolástica Moura Santos ${ }^{1}$ \\ http://orcid.org/0000-0002-3407-9496
}

\begin{abstract}
Resumo: Este artigo apresenta os resultados de análise realizada acerca dos documentos de caráter político e normativo que orientam a educação social. Tem como objetivos de pesquisa compreender os propósitos da educação social, bem como, analisar os caminhos percorridos visando objetivar aquilo a que se propõe. No que se refere ao primeiro aspecto, identificamos a prevalência de elementos objetivos e foco na aparente totalidade. No que diz respeito ao segundo aspecto, identificamos a centralidade na subjetividade e na imediaticidade. Tendo como suporte teórico a ontologia do ser social, buscamos elementos que nos permitiu empreender uma crítica radical no que se refere ao fato de a educação social, direcionada a indivíduos desvalidos, apontar como solução para os problemas sociais alterações de caráter imediato e subjetivo. Identificamos, portanto, que a educação social, ao seguir por esse viés, tende a servir mais aos interesses do capital do que ao projeto de transformação da sociedade.
\end{abstract}

Palavras-chave: Educação social. Sociedade capitalista. Transformação social.

\begin{abstract}
This article presents the results of an analysis of the political and normative documents that guide social education. Has as research goals to understand the purposes of social education, as well to analyze the paths covered in order to objectify what is proposed. With regard to the first aspect, we identify the prevalence of objective elements and focus on the apparent totality. With regard to the second aspect, we identify the centrality in subjectivity and immediacy. Having as theoretical support the ontology of the social being, we seek elements that allowed us to undertake a radical critique regarding the fact that social education, directed to underprivileged individuals, point as a solution to social problems immediate and subjective changes. We have identified, therefore, that social education tends to serve the interests of capital rather than the project of transforming society. Key words: Social education. Capitalist society. Social transformation.

1 Doutora em Educação pelo Programa de Pós-Graduação em Educação Brasileira da Universidade Federal do Ceará - UFC (2017); Mestre em Educação pela Universidade Federal do Piauí - UFPI (2010) e Licenciada em Pedagogia pela Universidade Federal do Piauí (2004). É Professora-pesquisadora da Universidade Federal do Piauí, Departamento de Fundamentos da Educação, área de Fundamentos Históricos e Culturais da Educação. É Líder do Núcleo de Estudos e Pesquisas em Educação e Emancipação Humana (NESPEM). Discute temas relacionados às políticas de educação para crianças e adolescentes pobres, tendo como centralidade as categorias trabalho e formação humana, e como recorte o Regime Militar e as políticas neoliberais implementadas a partir dos anos 1990 na América Latina, no Brasil e no Piauí.
\end{abstract}


Resumen: Este artículo presenta los resultados de análisis realizados sobre los documentos de carácter político y normativo que orientan la educación social. Tiene como objetivos de investigación comprender los propósitos de la educación social, así como, analizar los caminos recorridos buscando objetivar lo que se propone. En lo que se refiere al primer aspecto, identificamos la prevalencia de elementos objetivos y foco en la aparente totalidad. En lo que respecta al segundo aspecto, identificamos la centralidad en la subjetividad y en la inmediatez. Con el apoyo teórico a la ontología del ser social, buscamos elementos que nos permitieron emprender una crítica radical en lo que se refiere al hecho de que la educación social, dirigida a individuos desvalidos, apunta como solución a los problemas sociales alteraciones de carácter inmediato y subjetivo. Identificamos, por lo tanto, que la educación social, al seguir por ese sesgo, tiende a servir más a los intereses del capital que al proyecto de transformación de la sociedad.

Palabras clave: Educación social. Sociedad capitalista. Transformación social.

\section{INTRODUÇÃO}

Neste trabalho nos propomos a analisar os principais marcos políticos e normativos da educação social com o objetivo de responder às seguintes perguntas: $O$ que a educação social se propõe a objetivar? Como pretende objetivar aquilo a que se propõe? Entendemos que ao apreendermos os fins e os meios da educação social, considerando sua gênese histórico-ontológica, será possível compreender a função que ela ocupa no processo de reprodução da sociedade.

Os documentos analisados são a Declaração de New Cork de 1990, a Declaração de Barcelona de 2003, a Declaração de Montevideo de 2005, a Carta da Pedagogia Social (Brasil) de 2006, a Declaración de Valencia de 2012, a Declaración de Saragoza de 2014 e o Compromisso de Servilla de 2016. Além desses de cunho político, temos, ainda, os documentos de caráter normativo como o Código Deontológico da profissão do Educador Social, de Portugal, datado de 2001 e o Projeto de Lei N. 5346/2009, que dispõe sobre a regulamentação da profissão de educador(a) social no Brasil2.

Analisar a função da educação social no processo de reprodução da sociedade de classes implica retomarmos a discussão acerca da importância desse processo para a continuidade do movimento de humanização necessário à perpetuação do ser social. De acordo com Lukács (2013), todos os complexos sociais cumprem determinada função no processo de reprodução da sociedade, tanto o complexo primário que é o trabalho, quanto os complexos secundários como a linguagem, o direito, a política, a arte, a educação etc.

Entendemos, a partir de Lukács (2013) e Leontiev (1978), que o processo de apropriação do mundo por parte do indivíduo não se dá de forma natural. Essa apropriação pressupõe adequada atividade do indivíduo no sentido de se apossar dos fenômenos e

2 Foram esses os documentos que tivemos acesso depois de longo processo de busca em dissertações, teses, artigos e sítios eletrônicos. O critério para seleção dos trechos foi a pertinência. Alguns documentos são bem resumidos, com uma ou duas páginas, de forma que não tivemos muita escolha. Aqueles trechos que apontavam as respostas para as perguntas elaboradas foram destacados para análise. 
objetos do mundo. A função que a educação assume é justamente garantir que as novas gerações se apropriem do acervo material e cultural produzido pelas gerações precedentes, de modo que ao se apropriar desse acervo o indivíduo toma parte no próprio processo de desenvolvimento do gênero humano e se prepara para produzir o novo.

Como destaca Leontiev (1978), diferente dos animais inferiores, em que a herança genética é suficiente para desenvolver as características da sua espécie e cuja atividade se limita a atos de adaptação ao meio, o indivíduo precisa se apropriar de maneira ativa das aquisições do desenvolvimento do gênero humano, para realizar o seu próprio desenvolvimento ontogenético. Nesse processo, a educação cumpre a função de possibilitar ao indivíduo o acesso ao desenvolvimento sócio-histórico da humanidade.

A educação garante ao indivíduo a possibilidade de deixar de ser apenas mais um exemplar da espécie humana para se tornar um ser único, pois, a constituição da sua subjetividade se dá a partir das relações que estabelece com o mundo objetivo, mediatizadas pela educação. Nesse processo, explica Lukács (2013), tanto a educação em sentido lato quanto em sentido estrito tem sua função.

No que se refere especificamente à educação em sentido estrito, da qual tratamos aqui, ao mesmo tempo em que contribui para reprodução do gênero, reproduz a lógica social dominante. Assim, a educação em sentido estrito interage com a educação em sentido lato e ao mesmo tempo dela se diferencia, uma vez que não é dada espontaneamente. No capitalismo, sua principal função é preparar mão de obra necessária para abastecer a máquina produtiva, além de disseminar as ideias e os valores que dão legitimidade aos interesses dominantes (LUKÁCS, 2013).

A educação em sentido estrito, mesmo não sendo o único instrumento utilizado para garantir a internalização da lógica capitalista, cumpre importante tarefa nesse processo. Uma das principais funções da educação formal em nossa sociedade, conforme Mészáros (2005), é produzir quanta conformidade ou "consenso" ela for capaz e, assim, garantir o conformismo generalizado e a subordinação dos indivíduos às imposições da ordem social vigente.

Embora sua principal função seja essa, produzir conformidade, não é a única. A educação em sentido estrito também pode se constituir, mesmo que de forma embrionária, em instrumento de luta contra-hegemônica. Daí a necessidade, como afirma Mészáros, (2005, p. 57), de um movimento que se proponha a agir na contramão do sistema, que se apresente como "atividade contra-internalização". Um movimento que não se limite a negar a sociedade atual, mas, que seja capaz de definir objetivos abrangentes e propor alternativas ao que já existe. Essa educação "não é contemplativa, é ativa e dinâmica e abrange a situação objetiva, assim como a reação subjetiva das pessoas envolvidas" (MÉSZÁROS, 2005, p.57).

É com base nesses pressupostos que analisamos a função que a educação social, como complexo constituído no bojo das relações sociais, assume no processo de reprodução 
da sociedade capitalista. Para tanto, retomamos as questões norteadoras, uma vez que, as respostas nos ajudarão a entender as teleologias e as objetivações dessa educação que se coloca à frente na luta em defesa dos excluídos, daqueles ditos em situação de risco e vulnerabilidade social. Revelará se a educação social se impõe como instrumento, mesmo que embrionário, de combate às determinações do capital, como movimento contra-internalização, ou se limita a contribuir com a reprodução e perpetuação deste sistema, através do consenso e do conformismo.

Para compreendermos as respostas encontradas nos documentos em análise, organizamo-las em dois momentos: o primeiro momento expressa aquilo que é idealizado como principal objetivo da educação social, ou seja, seus fins, suas teleologias. O segundo revela as estratégias de objetivação daquilo que foi previamente idealizado, ou seja, as posições teleológicas. Posteriormente será possível perceber qual o momento predominante e quais seus becos sem saída.

\section{A PRÉVIA IDEAÇÃO: CENTRALIDADE DA OBJETIVIDADE E DAAPARENTE TOTA-} LIDADE SOCIAL

A prévia ideação é a capacidade, pertencente apenas ao ser social, de planejar suas ações antecipadamente. Essa capacidade surge com o desenvolvimento da consciência que se efetiva com e pelos atos de trabalho. O que diferencia o ser social dos animais meramente biológicos é precisamente a capacidade de planejar e objetivar atos de trabalho, ou seja, desenvolver atividade previamente idealizada visando garantir a sua existência.

Isso remete à Marx (2006, p. 212) quando afirma que o pior arquiteto leva vantagem em relação à melhor abelha, uma vez que antes de objetivar sua construção ela já existia como projeto em sua mente. "No fim do processo do trabalho aparece um resultado que já existia antes idealmente na imaginação do trabalhador". Disso decorre que o processo de trabalho não é apenas o ato de transformar a matéria, mas, o processo de imprimir à matéria algo que estava projetado na sua consciência.

Em conformidade com Marx, Lukács (2013, p. 44) explica que no trabalho estão postas, em germe, todas as determinações que constituem o ser social, de modo que "o trabaIho pode ser considerado o fenômeno originário, o modelo do ser social [...]”. O trabalho, o ato de transformar a natureza para retirar dela os meios de produção e de subsistência, é o ato gênese e constitui-se na protoforma de toda práxis social. É o modelo para todas as atividades do ser social. Sendo assim, se o trabalho - enquanto atividade de objetivação de algo na natureza que foi previamente idealizado na consciência - constitui-se em modelo para as demais práxis sociais, interessa-nos conhecer a prévia ideação que orienta as objetivações nessa práxis denominada educação social.

A esse respeito, os documentos analisados revelam que as teleologias que orientam a educação social tem como centralidade a objetividade e se propõe a agir aparentemen- 
te no âmbito da totalidade, pois, assume uma prática socioeducativa, responsabiliza-se pela educação de todos os membros da sociedade e visa garantir a transformação social. Entendem que a sociedade atual é excludente, produtora de sofrimentos diversos e que impõe aos indivíduos mais fragilizados uma vida de flagelos, privações e injustiça. O que a educação social pretende é garantir os direitos dos indivíduos, ditos, em situações de vulnerabilidade e risco social, promover a justiça social e construir outro mundo possível, como revelam estes enxertos extraídos dos documentos:

O Educador Social deve subordinar a sua actuação profissional a princípios como a igualdade de direitos, o exercício da liberdade, a promoção da paz, a prática da justiça, o exercício da tolerância e o respeito para com a Natureza (CÓDIGO DEONTOLÓGICO, PORTUGAL, 2001).

[...] Nossa profissão está baseada na prática socioeducativa (DECLARACIÓN DE BARCELONA, 2003 - tradução nossa).

Os educadores e educadoras sociais renovam o compromisso com a democracia, pela justiça social, em defesa do patrimônio cultural e dos direitos de todos os humanos, a partir da convicção de que outro mundo é possível (DECLARAÇÃO DE MONTEVIDEO, 2005 - grifo nosso - tradução nossa).

A Pedagogia Social [...] deve edificar-se sobre o princípio da responsabilidade educacional da família, do Estado e da sociedade com a Educação de todos os seus membros (CARTA DA PEDAGOGIA SOCIAL, BRASIL, 2006).

Reafirmamos e comprovamos a existência do campo da Educação Social como um trabalho específico orientado a garantir o exercício dos direitos dos sujeitos de nosso trabalho (PROJETO DE LEI N. 5346/2009).

Nesta situação de profunda crise econômica, empobrecedora e ameaçadora, especialmente para as pessoas com mais dificuldades socioeconômicas, educativas e culturais, as organizações profissionais de educadoras e educadores sociais, convencidas de que outra realidade é factível, de que outras políticas são possíveis e desejáveis, contribuímos e reivindicamos uma clara opção pela ação construtiva de uma sociedade centrada nos direitos básicos das pessoas (DECLARAÇÃO DE VALENCIA, 2012 - grifo nosso - tradução nossa).

Faz-se presente nesses escritos a defesa da justiça social, dos direitos humanos na sua totalidade e não apenas de um grupo ou de um segmento social, porém, com especial atenção aos indivíduos com mais dificuldades econômicas, educativas e culturais. Defende-se a construção de "outro mundo possível", outra realidade, outras políticas. Esse outro mundo possível é anunciado como uma sociedade calcada na democracia, na cidadania e no sistema de garantia de direitos que atualmente está ameaçado pela "profunda crise econômica". Afirmam:

Os objectivos do XII Congresso Mundial são facilitar o diálogo e a tomada de consciência que favoreça uma melhor compreensão internacional das necessidades dos jovens em dificuldade e desenvolver atividades construtivas para melhorar seu bem-estar em todo o mundo (DECLARAÇÃO DE NEW CORK, 1990 - tradução nossa). 
Declaramos: nosso compromisso com a cidadania em defesa do Estado de bem-estar social, baseado na Declaração Universal dos Direitos Humanos e que se expressa através do reconhecimento da nossa prática profissional (DECLARAÇÃO DE SARAGOZA, 2014 - tradução nossa).

Nos comprometemos a: intensificar nossa presença nos cenários políticos e sociais, defendendo políticas de bem-estar que permitam o pleno desenvolvimento das pessoas, renovando a maneira de fazer a política e criando relações econômicas que assegurem maior coesão social a partir do respeito a dignidade de todas e todos (COMPROMISSO DE SERVILLA, 2016 - tradução nossa - grifo nosso).

A garantia dos direitos, a plena cidadania, seria efetivada, segundo esses documentos, com o resgate do Estado de bem estar-social. Os educadores propõem intensificar sua atuação social, através de intensa "inserção nos cenários políticos". Esse retorno proporcionaria as condições econômicas favoráveis à coesão social.

As proposições dos educadores sociais, contidas nesses documentos, apontam para o âmbito de uma aparente totalidade, no sentido de que intencionam promover ações voltadas aos interesses coletivos. Isso indica que o foco dessas proposições está voltado ao aspecto objetivo da sociedade, considerando a economia e a política, entretanto, restringe-se às proposições do Estado de bem-estar que garantiria "os direitos de todos os seres humanos".

Isso nos remete às seguintes indagações: a educação social tem realmente interesse em defender o direito de todos os seres humanos? Inclusive dos ricos proprietários e exploradores? Daqueles que vivem na opulência, cercados de privilégios e com todas as leis operando a seu favor? Dá a entender que sim, uma vez que não tece críticas à sociedade capitalista, à lógica desumana da exploração, cujas situações de pobreza são elementos necessários à manutenção do seu sociometabolismo.

A partir dessa constatação é possível pressupor que as mudanças que a educação social se propõe a realizar devem ser empreendidas dentro do sistema capitalista sem modificá-lo, como rearranjos ou tentativas de humanizar o capital nos moldes do Estado de bem-estar proposto por Keynes ${ }^{3}$. A ideia é ajustar a sociedade dentro dessa lógica, apenas reorganizando-a de modo que a miséria não seja assustadoramente expressiva e venha a comprometer a tão desejada coesão social para, enfim, efetivar-se a cidadania. Mas, cidadania de quem?

Segundo Mészáros (2011), todos aqueles que defendem o sistema do capital utilizam justamente a democracia para argumentar que somente no capitalismo seria possível vivenciá-la. Para garantir falsa sensação de harmonia e coesão social, forja-se a ideia de que este sistema é perfeitamente administrável. Descaracteriza-se, de forma ideológica, os antagonismos de classes ao defender que o fato de os fortes devorarem os fracos faz par-

3 John Maynard Keynes, importante economista do século XX, defendeu uma política econômica cujo Estado deveria intervir por meio da regulação do setor privado e determinar as regras do mercado, tentando corrigir suas falhas. Deste modo, garantiria o crescimento da economia e a redução das desigualdades sociais com ampliação do emprego e crescimento dos salários. Seria o chamado Estado intervencionista. 
te de uma competição saudável numa sociedade em que todos possuem "oportunidades iguais".

Desconsidera-se que a miséria e a negação de direitos são intrínsecas à própria lógica burguesa, sobretudo, no atual contexto de crise estrutural do capital devido aos limites de expansão e acumulação que teve início nos anos 1970. Sendo assim, parece irrelevante defender o Estado de bem-estar social nos moldes keynesiano se o que tem prevalecido é o arrocho fiscal e a perda de direitos por parte dos trabalhadores como as principais medidas para salvar o sistema. O Estado de bem-estar social que a Europa e os Estados Unidos conheceram, ao qual a América Latina tanto almejou, não está mais na ordem do dia.

Esse sistema de garantia de direitos, denominado por Mészáros (2011) de sistema de duplo padrão, que proporciona situação de maior conforto aos trabalhadores dos países do capitalismo central, em relação aos trabalhadores dos países da periferia do capital, está ameaçado. Isso ocorre porque esse sistema de duplo padrão não é permanente, ele se mantem enquanto estiver garantido o processo de expansão e acumulação do capital que garante o crescimento dos lucros. Essa é a condição necessária para manter em níveis confortáveis o padrão de vida dos trabalhadores, dentro do nível tolerável de exploração. No entanto, ao menor sinal de crise econômica os primeiros ajustes realizados dizem respeito aos cortes nos direitos dos trabalhadores.

É exatamente isso que tem ocorrido na Europa e nos Estados Unidos, com repercussões na América Latina, a redução de direitos historicamente conquistados que, junto com o desemprego estrutural, tem empurrado para baixo o padrão de vida da classe trabaIhadora. Esse fato tem agravado consideravelmente os problemas sociais, principalmente se levarmos em consideração a situação dos imigrantes, dos negros, das mulheres etc. $O$ rebaixamento no padrão de vida das classes trabalhadoras foi se agravando ainda mais com o predomínio, desde o final dos anos 1980, das políticas neoliberais de livre mercado e privatização, o chamado Estado mínimo.

É esse o cenário que justifica a luta dos educadores sociais pelo retorno do Estado de bem-estar social, considerando que a barbárie não é mais possibilidade, como postulou Rosa Luxemburgo, a barbárie reina na sociedade do capital em crise. Ela se manifesta no crescente exército de desempregados e excluídos do sistema que ameaçam a ordem estabelecida na sociedade. Daí advém a preocupação dos educadores sociais em garantir a coesão social, pois, ao fim e ao cabo, isso é o que todos querem. No entanto é preciso se ter claro: coesão por que e para que?

As políticas neoliberais às quais nos referimos - cujo objetivo é tentar suavizar os efeitos da crise do capital na ótica do mercado - sendo por si mesmas responsáveis pelo acirramento das desigualdades sociais, são ao mesmo tempo desencadeadoras de insatisfações e revoltas. Daí a necessidade de ações voltadas à conformação, ao apaziguamento e, quando necessário, à repressão por parte do Estado em nome do "bem comum" e da coesão social. 
Emerge, então, uma exigência de que a educação social se auto-examine para tentar descobrir até que ponto está lutando pelos interesses dos indivíduos ditos vulneráveis ou apenas cumprindo as determinações do capital pelas vias do Estado. Isso porque tanto o capital quanto o Estado encontram na coesão social o elemento fundamental para exercer firmemente o seu poder e garantir a efetivação das tais políticas neoliberais, sobretudo, nos países da periferia onde se impõem de maneira mais intensa.

Fernandes (1995) chama a atenção para duas consequências negativas, dentre outras, da disseminação dos ideais perversos do neoliberalismo. Uma se refere ao fato de que na América Latina se realizou desmonte da soberania nacional, ao contrário do que ocorre na Europa e nos Estados Unidos. A outra consequência diz respeito ao que ele denomina de viragem política de caráter essencialmente antidemocrático nas sociedades que adotam o neoliberalismo, revelados no crescimento de movimentos de cunho racista e chauvinista na Europa. O que se verifica é a "adoção de medidas cada vez mais restritivas da democracia representativa e do pluralismo democrático" (FERNANDES, 1995, p. 56-57).

Atualmente podemos observar em todo o mundo o avanço de ideias conservadoras e o recuo dos direitos democráticos. No Brasil, é comum a ampla disseminação de ideias neonazistas e neofascistas, o crescimento da ultradireita e a defesa explícita de regimes políticos ditatoriais nos moldes da Ditadura Militar circulando livremente nas manifestações de rua e nas redes sociais.

Outro exemplo que pode ser citado por evidenciar essa coerção do Estado sobre a sociedade, disfarçada na forma de democracia, é a centralização na definição dos currículos escolares. Embora a LDB 9394/96 determine a descentralização da educação através da delegação de tarefas para estados e municípios, todo o processo de implementação dos Parâmetros Curriculares Nacionais da Educação Brasileira, nos anos 1990, considerando desde sua elaboração até sua efetivação, deu-se de cima para baixo, profundamente marcado por uma postura antidemocrática.

É factível destacar, ainda, a disseminação às vezes explícita, às vezes disfarçada, da lógica do mercado e dos ideais neoliberais no referido documento, como o discurso das competências, do empreendedorismo, da flexibilidade, da criatividade, da capacidade de adaptação e toda essa lógica meritocrática que transfere para os sujeitos a responsabilidade pelo seu sucesso ou fracasso. Do mesmo modo deve ser considerada a centralização do sistema nacional de avaliação, como o ENEM, ENADE, Provinha Brasil etc., no governo federal.

A própria reforma do Ensino Médio, instituída pela Lei 13.415/2017 revela esse caráter conservador e classista, intencionalmente planejada para desarticular as disciplinas que mais favorecem o debate e o desenvolvimento do senso crítico. Não é possível acreditar que se dá por mero acaso o desmerecimento de disciplinas como História, Geografia, Filosofia, Sociologia e Artes no currículo da educação básica. São explícitas as manobras que buscam o esvaziamento curricular para priorizar a formação profissionalizante, provocando 
retrocesso que, certamente, impactará mais diretamente os alunos da escola pública do que os consumidores do ensino privado (AMORIM; SANTOS, 2016).

Com base no exposto, é possível pressupor que se trata de tentativa das camadas detentoras do poder de conter a população insatisfeita. Para compreendermos esse processo é preciso considerar o medo que a burguesia possui de que a crescente desigualdade social - em decorrência da crise do capital e agravada com a omissão do Estado, devido às políticas de cunho neoliberal - possa se constituir em estopim para organização das lutas sociais contra a opressão.

Isso justifica as ações do Estado tanto através do seu aparato de repressão quanto da disseminação de ideologias que reforçam sua lógica perversa. Essa disseminação se dá através dos seus intelectuais, da reprodução desses ideais nas políticas públicas, sobretudo, com a ajuda dos instrumentos de convencimento como a mídia, as religiões e com especial destaque para a educação. Tudo em nome da tão desejada coesão social que os documentos da educação social trazem à baila como bandeira de luta.

Isso nos leva a defender a ideia de que a democracia no sistema capitalista é no máximo formal, pois, a ordem democrática que prevalece se encerra numa mera organização política. É preciso considerar os limites dessa democracia numa sociedade capitalista, cujos princípios que regem sua lógica, ou seja, a exploração e desigualdade, são expressamente contraditórios em relação aos princípios democráticos da igualdade e da liberdade.

Faz-se necessário indagar sempre: é possível a democracia e a cidadania numa sociedade com alarmantes índices de pobreza? Por outro lado, é possível eliminar a pobreza numa sociedade dominada pela lógica capitalista, sobretudo, de formato neoliberal? Essas são de fato demandas incompatíveis.

A instauração da democracia burguesa não é suficiente para revogar as determinações do capital, como a exploração do homem pelo homem e os inconciliáveis antagonismos de classes. É nesse sentido que Borón (1995) defende que ao nos referirmos à democracia devemos considerar seu sobrenome, uma vez que estamos nos referindo ao "capitalismo democrático". Nesse caso o capitalismo seria o substantivo e a democracia apenas a adjetivação. Isso significa que as regras do capital que a tudo subjuga, abarca também os ideais democráticos adequando-os aos seus interesses e conveniências. Portanto,

Quando os pobres se transformam em indigentes e os ricos em magnatas, sucumbem a liberdade e a democracia, e a própria condição do cidadão - verdadeiro fundamento sobre o qual se apoia a democracia - se deteriora irreparavelmente. A liberdade não pode sobreviver onde o cidadão indigente está disposto a vendê-la por um "prato de lentilhas", e um outro disponha de riqueza suficiente para comprá-la ao seu bel-prazer. Nessas condições a democracia se converte em um ritmo farsesco e se esvazia de todo conteúdo (BORÓN, 1995, p. 71). 
Isso revela a impossibilidade de efetivação da cidadania e da democracia numa sociedade marcada pela desigualdade de classes. No entanto, na concepção de democracia burguesa é indiferente se o indivíduo detém a posse dos meios de produção ou se é explorado no processo produtivo. Nessa concepção todos são cidadãos, embora o verdadeiro exercício da cidadania se limite ao âmbito das classes detentoras do poder econômico e político (BORÓN, 1995).

Essas questões precisam estar claras aos educadores sociais quando se dispõem a defender a democracia e a cidadania numa sociedade regida pelas leis do mercado. É preciso compreender os limites da luta pelo retorno do Estado de bem-estar social, num contexto de crise estrutural do capital no qual reinam as políticas neoliberais. É necessário refletir sobre os processos utilizados para conformar os indivíduos em relação às situações de desigualdades sociais, uma vez que as lutas comumente se dão pela redução, não pela eliminação da pobreza. As bandeiras são desfraldadas em defesa de uma sociedade mais justa e mais igualitária, não de uma sociedade plenamente justa e igualitária.

As propostas idealizadas pela educação social expressas nos documentos - por não atacarem as determinações do sistema capitalista, nem criticarem a lógica perversa que produz e alimenta a pobreza através da exploração - mesmo apontando para o campo da objetividade e defendendo o bem comum, limita-se apenas a uma aparente totalidade social. Dizemos aparente porque ao mesmo tempo em que se refere ao patrimônio cultural comum, à garantia de direitos de todos os seres humanos e à construção de outra sociedade possível, descamba no limitado conceito de democracia burguesa.

Isso revela que desejar não é suficiente. Como explica Marx (2011, p. 25), embora os homens façam a história, eles não a fazem conforme suas vontades, em circunstâncias por eles escolhidas. Eles a fazem a partir do que foi historicamente dado, uma vez que "a tradição de todas as gerações passadas é como um pesadelo que comprime o cérebro dos vivos". Os desdobramentos desse fato, conforme Lukács (2010, p.89), é que "também a generidade humana não é capaz de desenvolver-se sem que os indivíduos tomem posições conscientes e práticas quanto aos problemas nela contidos". E isso não se dá de forma natural, por herança biológica.

É necessário que os indivíduos queiram e ajam, queiram coletivamente e ajam coletivamente. Não um querer desconectado do real, das reais possibilidades resultadas das causalidades postas. É preciso que ajam, não apenas conforme suas vontades, mas, considerando as multideterminações sociais e a herança das gerações passadas. É preciso compreender o real e fazer as escolhas que apontam na direção da verdadeira liberdade humana. Do contrário, até mesmo as limitadas idealizações continuarão sendo apenas idealizações.

É preciso agir, a partir do que temos, para construir aquilo que desejamos. É com essa compreensão que analisaremos as ações empreendidas pelos educadores sociais no sentido de conquistarem aquilo a que se propõem, ou seja, os meios definidos para 
atingirem os fins por eles propostos, que é garantir os direitos de todos os seres humanos através do fortalecimento da cidadania. É isso que estamos denominando de posições teleológicas dos educadores sociais.

\section{AS POSIÇÕES TELEOLÓGICAS: CENTRALIDADE DA SUBJETIVIDADE E DA IMEDIATICIDADE}

A educação social lida com um complexo de problemas que é específico dessa área. Embora idealize objetivar teleologias no campo da totalidade social, ela atua no campo do imediato, precisa dar respostas a situações postas pelas demandas sociais com nítido caráter de urgência. Isso está posto na própria essência da educação social, uma vez que é da necessidade de lidar com situações urgentes que ela surge. No cotidiano do seu fazer pedagógico, diante das situações de pobreza, de desamparo ou de risco e vulnerabilidade, como preferem, não há margem para complexas discussões, é necessário agir.

O educador social depara-se com a face mais perversa do sistema capitalista, age tentando equilibrar as insuperáveis distorções provocadas pelos antagonismos de classes, como a exclusão, o abandono, o desamparo e toda sorte de violência. Experimenta situações que lhe exigem respostas rápidas, uma vez que as demandas são de fato imediatas. Para tanto precisa estar preparado física, intelectual, moral e psicologicamente.

Disso decorre que, embora as questões mais amplas, relacionadas à aparente totalidade social, aos aspectos objetivos da sociedade, sejam apontadas anteriormente como a centralidade das suas idealizações, no seu agir cotidiano elas ocupam posição de menor destaque. É isso que indicam as informações encontradas nos documentos, que apontam para a imediaticidade ao se restringirem ao âmbito da subjetividade dos indivíduos envolvidos no processo.

Essa imediaticidade se explicita nas propostas de ações dos educadores sociais visivelmente voltadas à promoção do indivíduo. Por um lado, foca nos próprios educadores através da defesa tanto da formação quanto do reconhecimento da profissão, da constituição do senso de coletividade, da promoção de investigações, por outro, evidencia os sujeitos a serem atendidos pela educação social, nos quais devem ser desenvolvidas qualidades tidas como válidas para sua inserção na sociedade. No que se refere à figura do educador, os documentos afirmam que:

Promover investigações nacionais e internacionais no âmbito dos jovens em dificuldade (DECLARAÇÃO DE NEW CORK, 1990 - tradução nossa).

DECLARAMOS a vontade de participar da construção de uma Europa que favoreça a mobilidade dos profissionais; a vontade de participar da construção comum da profissão do educador(a) europeu; a vontade de direcionar nosso conhecimento para a definição dos critérios de reconhecimento das qualificações profissionais dos educadores sociais na Europa; a vontade de definir princípios éticos comuns para 
todo o coletivo profissional da Europa; a necessidade de ter uma formação em nível 4 [...] (DECLARAÇÃO DE BARCELONA, 2003 - tradução nossa).

[...] é um imperativo a consolidação da figura do Educador ou Educadora Social, sua integração ao trabalho e sua organização como coletivo (DECLARAÇÃO DE MONTEVIDEO, 2005 - tradução nossa).

Como consequência das discussões, reflexões e propostas do I Congresso Internacional de Pedagogia Social [no Brasil], entendemos oportuno que as universidades públicas - federais, estaduais e municipais - prioritariamente, orientem seus esforços para a formação de profissionais capazes de fazer frente aos desafios que a sociedade brasileira enfrenta, estruturando linhas de pesquisa e cursos de graduação, de especialização, de mestrado e doutorado em Pedagogia social como meio efetivo de criar o campo, o currículo e a profissão do pedagogo social, tal como ocorre em países como Chile, Portugal, Espanha e Alemanha, dentre outros (CARTA DA PEDAGOGIA SOCIAL, BRASIL, 2006).

Atuação efetiva e com firmeza, colaborando com outras instituições, organizações e entidades sociais e educativas, fazendo o estabelecimento de programas de formação permanente, de ação socioeducativa e cultural, de investigação reflexão, entre outros, dando respostas às inquietudes e necessidades das e dos educadores sociais (DECLARAÇÃO DE VALENCIA, 2012 - tradução nossa).

DECIDIMOS: [...] trabalhar conjuntamente com o objetivo de alcançar o reconhecimento da profissão de educadora e educador social na Europa; chegar a um consenso e apresentar, ao órgão responsável, uma proposta de regulamentação dos princípios comuns de formação; Favorecer a mobilidade das e dos profissionais na Europa (DECLARAÇÃO DE SARAGOZA, 2014 - tradução nossa).

Nos comprometemos a: consolidar o desenvolvimento profissional das educadoras e dos educadores sociais a partir de uma formação inicial que nos capacite para o desenvolvimento das nossas funções e a partir de uma formação permanente que atualize nossas capacidades de dar respostas às transformações sociais (COMPROMISSO DE SERVILLA, 2016 - tradução nossa).

Esses fragmentos expressam o predomínio da imediaticidade através da defesa da qualificação, reconhecimento e valorização profissional, da criação de cursos de formação, da organização de currículos, do desenvolvimento de competências, da constituição da coletividade e do desenvolvimento da pesquisa. Ou seja, são ações que mesmo apontando para aspectos objetivos da realidade, sua finalidade primeira é impactar no âmbito da singularidade dos indivíduos que compõem o coletivo dos educadores sociais.

Essa necessidade de priorizar a formação e a profissionalização, manifestada pelos educadores sociais, não nasce apartada do real, não se trata de discurso suspenso no ar, ela nasce na relação com o contexto objetivo ao qual estão inseridos. Os educadores sociais em geral trabalham de forma precarizada, sem reconhecimento da profissão, vinculados a instituições públicas ou não-Governamentais, alguns voluntários, muitos com formação em nível médio ou até fundamental.

Trata-se de educadores que lidam muitas vezes com situações de negação da vida, atuam com indivíduos inseridos em contextos desumanizadores, com famílias imersas na mais absoluta miséria, com jovens vítimas de dependência química, do desemprego e de 
todo tipo de violência. Os educadores sociais convivem com um histórico de negação de direitos ao qual também se inserem ao terem seus próprios direitos negados.

Pesquisa realizada por Cunha (2012) na FUNCI (Fundação da Criança e da Família Cidadã), em Fortaleza, revela que muitos educadores sociais são jovens egressos de instituições ou projetos sociais. Isso significa que muitos deles já estiveram na condição de crianças e adolescentes, ditos em situação risco e vulnerabilidade social, e retornam na condição de educadores.

Conforme o coordenador de um desses projetos entrevistado por Cunha (2012, p. 76), "esses jovens muitas vezes vêm de situações complicadas, muitas vezes estavam em situação de vulnerabilidade e essa situação não se supera quando ele é contratado". De acordo com o pesquisador, dentre as principais limitações apontadas na prática desses educadores estão as fragilidades de sua formação escolar, que contribui para visível dificuldade na condução de grupos e no preenchimento de relatórios, visto que muitos são contratados antes de concluir a educação básica.

Num sentido diferente aponta pesquisa realizada por Paiva (2015) com educadores sociais de rua, em Porto Alegre e Vitória. Conforme a pesquisadora, todos os educadores sociais já possuíam formação em nível superior, alguns com pós-graduação, inclusive em nível de mestrado. No entanto, aproxima-se da pesquisa anterior na medida em que os educadores sociais revelam reconhecer a necessidade de uma formação contínua capaz de orientá-los na sua atividade nas ruas.

Silva (2008), ao analisar a construção da identidade dos educadores sociais, também constata que os sujeitos da sua investigação já possuem formação inicial em nível de graduação (Pedagogia, Psicologia, Serviço Social etc.), mas reclamam condições materiais para investimento na continuidade dos seus estudos. Outro fato revelado nessa pesquisa que se aproxima dos dados apresentados por Cunha (2012) é o baixo padrão de vida dos educadores sociais que os nivela às condições de existência experimentadas pelos sujeitos da sua ação.

Conforme Silva (2008, p. 90), uma das grandes insatisfações apontadas pelos entrevistados refere-se justamente às precárias condições de vida determinadas pelos parcos salários, "impondo-lhes privações semelhantes as da população por ele atendida". O pesquisador alega que os educadores sociais, ao se sentirem privados de condições materiais para uma vida digna, não percebem necessária distinção entre eles e seus educando e acabam sentindo-se desautorizados no desenvolvimento da sua ação interventiva.

Além dos baixos salários, ainda de acordo com Silva (2008), os educadores sociais se queixam das precárias condições de trabalho, da descontinuidade dos projetos, bem como da falta de investimento em sua formação, da burocracia e da dissidência entre os interesses políticos e a prática que desenvolvem. Para esses educadores, a sociedade de modo geral atua no sentido de contrariar qualquer possibilidade de transformação das situações de desigualdade sociais. 
No que se refere às queixas dos educadores sociais, evidenciadas por Paiva (2015), destaca-se a inexistência de reconhecimento oficial da sua profissão. Ressaltam que seu fazer está amparado no conhecimento advindo da experiência devido à falta de formação e de sistematização metodológica. Isso gera uma indefinição nas funções que deve desempenhar.

Outro aspecto que chama a atenção, segundo Paiva (2015), é a diversidade de formação desses profissionais que vai do nível médio e técnico ao superior, como oficineiros, artesãos, artistas, mestre de capoeiras, arte-educadores, monitores, pedagogos, sociólogos, psicólogos, assistentes sociais, advogados, historiadores, dentre outros. Ela evidenciou que a diversidade formativa e a imprecisão conceitual é tão expressiva que chega a causar confusão até mesmo entre os próprios educadores.

Isso pode ser compreendido como reflexo da inexistência de políticas de regulamentação das contratações, o que contribui para que os educadores sociais recebam denominações as mais diversas, chegando a ser denominado de formadores, cuidadores, sócio-educadores, agente de proteção social, mães sociais etc. Esse fato pode se constituir em um dos elementos que contribui para fragmentação da categoria que inviabiliza ou, em última instância, dificulta a luta por reconhecimento e melhores condições de trabalho.

Entendem que para lutar por melhoria das suas condições de vida e de trabalho necessitam do mínimo de unidade categorial, de sentimento de pertença a um grupo profissional, algo que no momento está limitado pela fragmentação. Além disso, necessitam de sólida formação intelectual, daí o foco das suas ações nas questões mais imediatas. A esse respeito, Paiva (2015) afirma que os educadores sociais revelam certo nível de angústia pelo fato de sua profissão ainda não ser oficialmente reconhecida, o que leva à imprecisão das atribuições e a um aparente espontaneísmo. Segundo a pesquisadora, é como se o educador desenvolvesse as atividades de uma profissão que inexiste.

Levando em consideração as precárias condições em que os educadores sociais desenvolvem suas atividades no Brasil; considerando, ainda, a falta de cursos de formação inicial em educação social, que possa orientar esse profissional no seu fazer pedagógico; bem como as situações de nivelamento entre suas condições de vida e a das populações atendidas; entendemos que a luta por formação, por valorização e reconhecimento profissional não deixa de ser necessária e urgente.

Do mesmo modo, é possível perceber que essa urgência acaba desvirtuando o foco da educação social, que deveria estar orientado para a transformação da sociedade na sua totalidade e não apenas para alteração das suas condições de vida. No entanto, isso apenas reforça a máxima marxiana de que a base material da existência tem prioridade ontológica em reação às demais dimensões da vida humana. Como afirmam Marx e Engels (2007), o indivíduo faz a história, mas, para isso precisa estar vivo e em condição de fazê-la. Precisa comer, vestir, abrigar-se e satisfazer tantas outras necessidades postas pela sociedade a qual está inserido. 
Assim, a formação do educador social se apresenta tanto como condição para obter reconhecimento profissional e melhorar suas condições de vida, quanto para se instrumentalizar adequadamente para o exercício do seu fazer cotidiano. É nesse sentido que Bezerra (2011) - ao relatar as experiências no desenvolvimento do projeto Integração AABB Comunidade, no qual, uma das atividades desenvolvidas diz respeito à formação de educadores sociais - afirma que os processos formativos são elementos indispensáveis àquele que pretende atuar nesse projeto com crianças e adolescentes.

Nessa mesma direção aponta Gonzalez (2011) ao afirmar que a aquisição de competências seria uma forma de se empoderar para resolver problemas de ordem pessoal e grupal. Empoderar, segundo ele, seria tornar o indivíduo capaz de agir dentro da sua comunidade a partir das suas próprias convicções, dos seus conhecimentos e habilidades. Muitas vezes, segundo o pesquisador, a incapacidade dos educadores lidarem com problemas relacionados aos jovens se dá em decorrência do distanciamento entre os educadores e os educandos.

Por isso é fundamental, conforme Gonzales (2011, p.126), aos educadores sociais ressignificar sua função e desenvolver algumas competências que são necessárias à sua ação interventiva, como "facilidade de comunicação, dinamismo, criatividade, liderança e iniciativa, para realizar com eficácia o trabalho de mediador no grupo de alunos sob a sua responsabilidade".

Ainda a esse respeito, o pesquisador afirma que o educador social enxerga os problemas sociais com olhar diferenciado, por possuir sensibilidade para as questões sociais. Desse modo, a educação social teria capacidade "metaeducativa" compreendida no sentido de que exerce função que vai para além do imediato e do convencional, "na medida em que auxilia o educador a lidar com a resiliência, a desenvolver sua capacidade de superação das adversidades e a resistência às frustrações, a reagir, deixar o sofrimento para trás e recuperar-se em prol de uma causa maior".

A partir do que expõem os documentos, em diálogo com os autores citados, fica explícita a defesa da superação, da autodeterminação e do desenvolvimento de qualidades pessoais como condição necessária ao enfrentamento das mazelas sociais, ou seja, como meio para garantir a proteção e os direitos dessas crianças e adolescentes. Nesse caso, a transformação que deve ser processada no âmbito do indivíduo, ou seja, no educador social, alterando sua subjetividade, seriam suficientes para orientar o seu agir e transformar a realidade social conforme se propõe.

Entretanto, essa transformação deveria ocorrer não só no que se refere à subjetividade dos educadores sociais, mas também no âmbito dos sujeitos por eles atendidos. Assim, para os educandos saírem da condição de vulneráveis e serem inseridos na sociedade, seria necessário desenvolver, através da ação dos educadores, determinadas qualidades subjetivas, como revelam os trechos dos documentos normativos apresentados a seguir: 
O educador social deve procurar desenvolver nos utentes competências que thes permitam uma positiva integração social no contexto em que vivem. Deve procurar o desenvolvimento integral do pessoal sustentado em atitudes de respeito, criatividade, iniciativa, reflexão, coerência, sensibilidade, autonomia, fomentando a confiança e autoestima. O Educador Social deve conscientizar o utente do problema que ele atravessa e esclarecer os objetivos e a amplitude da sua actuação profissional. [...] O Educador Social deve desenvolver com os utentes uma relação educativa ideologicamente desinteressada que promova o auto conhecimento cultural e o reconhecimento da multiculturalidade (CÓDIGO DEONTOLÓGICO, PORTUGAL, 2001 - grifos nossos).

Educador Social. Descrição Sumária: Visam garantir a atenção, defesa e proteção a pessoas em situações de risco pessoal e social. Procuram assegurar seus direitos, abordando-as, sensibilizando-as, identificando suas necessidades e demandas e desenvolvendo atividades e tratamento (PROJETO DE LEI, BRASIL, 2009).

Essas passagens dos documentos reafirmam o anteriormente anunciado, o fato de que o movimento da educação social vem apontando para o âmbito do imediato e da subjetividade, descolada de sua interação com a objetividade. A função que a educação social assume é desenvolver nos sujeitos atendidos características subjetivas, ou seja, atitudes de respeito, criatividade, iniciativa, reflexão, coerência, sensibilidade, autonomia, confiança, autoestima etc. Acima de tudo, deve promover o desenvolvimento de competências que Ihes permitam uma integração social no contexto ao qual pertencem. Esta seria a forma de garantir defesa e proteção àqueles que estão em situação de risco e vulnerabilidade social, ou seja, os indivíduos pobres.

Certamente não há qualquer inconveniente em pretender desenvolver qualidades tão distintas nos sujeitos atendidos pela educação social. Essas são, de fato, características imprescindíveis para vida em sociedade, no entanto, esses documentos não deixam claro que o desenvolvimento de tais atributos, embora essencial, não é suficiente. Pior ainda, pressupõem "relação educativa ideologicamente desinteressada", como se fosse possível incorporar neutralidade às ações e relações humanas, sobretudo, quando o que está em pauta é a educação.

De acordo com os documentos, desenvolver as características subjetivas ou as tais competências é o que permite a esses sujeitos uma "positiva integração social no contexto em que vivem", mesmo que nesse contexto imperem a miséria, a exclusão, a violência, a discriminação e a negação à vida. Nesse caso, o educador terá a função de explicar e esclarecer ao educando acerca dos problemas nos quais está inserido.

Isso nos remete a outras perguntas: ao defendermos que os sujeitos atendidos pela educação social devem ser inseridos em seus contextos, sem discutir as condições materiais prevalentes e sob quais termos dar-se-á essa inserção, não estaríamos apenas validando a realidade posta? Esses indivíduos não merecem ser preparados para ir além do seu contexto de exclusão, ou seja, para transitar em contextos outros?

Quando o Código Deontológico afirma que "o Educador Social deve conscientizar o utente do problema que ele atravessa e esclarecer os objetivos e a amplitude da sua actua- 
ção profissional", não deixa claro se faz referência aos preceitos pestalozzianos que consistem em preparar as crianças das camadas pobres para serem pobres e se conformarem com isso, ou, se está se referindo a uma conscientização crítica a respeito da sua condição de classe, dos processos históricos de produção e manutenção da pobreza.

Essa reflexão crítica é fundamental para a tomada de consciência de classe, visto que a primeira condição para o indivíduo pretender mudar a realidade objetiva na qual está inserido é conhecer a sua situação. É necessário entender sobre quais bases ela se dá, a partir de quais relações, suas mediações e os instrumentos de luta, não para aceitá-la mas para lutar contra.

Não pretendemos, com isso, cair no idealismo utópico e defender que a conscientização é ferramenta suficiente para o processo de libertação e garantia de emancipação. Pois, conforme Leontiev (1978, p. 96), "a consciência não pode ser compreendida a partir de si própria" uma vez que seu desenvolvimento se dá na processualidade histórica, na relação com a objetividade do mundo real. É nessa interação que nasce o reflexo consciente como resultado da relação que se estabelece, no seu interior, entre sentidos e significados.

É na interação com o mundo, no movimento de adaptação e transformação que o indivíduo constrói sua consciência e se torna humano, explica o teórico russo. Seus sentidos e significados são produzidos nessa simbiose, do mesmo modo, suas percepções, sensações, representações etc., ou seja, o conteúdo sensível. Assim, para transformar os sentidos e significados produzidos e apropriados pelo indivíduo e alterar suas percepções e representações do mundo, não basta agir exclusivamente sobre ele, é necessário alterar a realidade do mundo objetivo no qual essas produções são processadas.

No entanto, para agir no plano da objetividade visando transformá-la, a tomada de consciência acerca do real é elemento fundamental. O indivíduo precisa reconhecer-se como explorado, como excluído, precisa compreender e desvelar os diversos instrumentos de opressão e de conformação utilizados pelas classes dominantes. Isso é condição para aqueles que estão sob a foice da opressão se movimentarem no sentido de buscar formas de organização para a luta, visando a justiça social.

É preciso, então, rever o conceito de protagonismo que comumente aparece na literatura da área. O pobre é protagonista porque na sua organização e luta estão postas as possibilidades de emancipação ou seu protagonismo se limita a ações empreendedoras dentro da sua comunidade? É preciso cautela com o discurso do protagonismo, pois, é próprio do Estado transferir tanto a responsabilidade pelos problemas sociais, quanto sua solução, para os próprios indivíduos e suas comunidades. É daí que advém o discurso do empreendedorismo, do protagonismo juvenil e do empoderamento individual.

Não podemos desconsiderar a situação de penúria na qual estão inseridos esses sujeitos, partes de uma sociedade que se sustenta no princípio da desigualdade. São indivíduos que convivem cotidianamente com a incoerência dessa sociedade que põe de um lado a miséria do grupo ao qual pertencem e do outro a opulência dos privilegiados; de um 
lado a dura rotina de negação, privação e preconceito, do outro o apelo ao consumismo, ao desperdício e à ostentação.

A educação social não pode assumir a função de garantir a conformação desses sujeitos. Ao contrário, deverá assumir a função de promover a criticidade, a capacidade analítica, a perscrutação e a contestação, o desejo e a capacidade de organização para luta. Ao invés de desenvolver competências visando à inserção do indivíduo no contexto desumanizador ao qual pertence, deve propor a organização do enfrentamento à situação de degradação humana que, em geral, prevalece nesses contextos. Do contrário será mero instrumento de controle do Estado e reprodução do capital.

Segundo Nuñes (2009), as transformações sociais provocadas nas últimas décadas do século XX, em função da dita globalização, contribuíram para acentuar a desagregação dos setores sociais, o que deixou os indivíduos largados a própria sorte. Isto não significa que antes inexistisse sistema de controle, na verdade o que temos agora são novas modalidades de controle social em busca da suposta ordem.

A solução que se apresenta, conforme Nuñes (2009, p. 247), de simplicidade extraordinária, é que cada um deve vigiar a si mesmo, ou seja "cada cual, entonces, deberá vigilar por su próprio bienestar"4. Assim, aquele que está próximo já não é mais alguém suscetível ao estabelecimento de laços sociais, apenas rival. Segundo a pesquisadora, é nessa vigilância pós-moderna que se insere o retorno do modelo higienista. Essas mudanças produzem uma redefinição nas instituições sociais e, simultaneamente, nos profissionais que nelas atuam.

Para Nuñes (2009, p. 248), o que se busca é, sob o discurso da prevenção, uma sociedade sã, "saneada por la erradicación (o el control directo), de aquello que se define como peligroso" ${ }^{5}$, pois o que mudou do século XIX ao século XX foi apenas os nomes que definem os perigosos e os modos de submetê-los a controle. De modo que as formas de gestão dos ditos perigosos, são empreendidas por meio de novos instrumentos de intervenção social, muitas vezes definidos como intervenção sócio-educativa. Faz-se um tipo de limpeza nos bairros ondem vivem indivíduos considerados perigosos, conflitivos, simplesmente pelo fato de viverem onde vivem, de serem pobres, jovens sem futuros, incapazes de gerir sua própria empregabilidade.

Ainda de acordo com Nuñes (2009), o vínculo existente entre determinadas políticas sociais, as tecnociências apoiadas em um discurso neohigienista e trabalhadores do campo social e educativo, é a gestão diferencial de populações (ou de algumas populações) mediante programas de intervenção social direta, em nome da prevenção de conflitos.

O renascimento do educador de rua, segundo a pesquisadora, não está alheio a esses fatos. Muitos projetos sociais são apenas instrumentos de controle social que, em nome

4 "Cada qual, então, deverá velar por seu próprio bem-estar" (NUÑES, 2009, p. 247).

5 "saneada pela erradicação (ou controle direto), daqueles que se definem como perigosos" (NUÑES, 2009, p. 248). 
da prevenção, lançam mão de noções de educação e participação para definirem meios de gestão e avaliação de certos setores populacionais. Disso decorre que uma das funções da pedagogia social é desmascarar a lógica higienista, a lógica do controle social, pondo em evidências suas metamorfoses e seus disfarces. As políticas sociais, quando não são interrogadas acerca dos resultados da sua ação, acabam por promover aquilo que dizem combater.

Entender essas questões postas por Nuñes (2009) são fundamentais para compreender que muitas vezes a educação social é utilizada apenas como instrumento de controle e de conformação das populações pobres, excluídas e ditas perigosas. É esse o risco que se corre quando o que se defende é apenas a inclusão pela inclusão, sem questionar as condições em que se dá essa inclusão e o contexto no qual esses sujeitos serão inseridos.

Mais insensato é não defender o direito e a possibilidade de permitir a esses indivíduos tomarem parte na produção material e cultural da humanidade. Com relação a essa questão, Bralich (2012) apresenta posicionamento, no mínimo, controverso. Para ele, não devemos insistir em relacionar a pedagogia social ao problema da inclusão social, pois, este problema é de competência das políticas públicas, não da educação social.

O pesquisador desconsidera a vinculação existente entre o desenvolvimento e a ampliação das áreas de atuação da educação social e a implementação de políticas públicas. O que ele propõe à pedagogia social é, diante das situações de marginalidade, analisar como é a cultura do marginalizado e definir as possibilidades de junto com ele construir novo modelo cultural, ao invés de simplesmente inclui-lo na cultura dominante.

Embora não descambe no campo da subjetividade, Bralich (2012) detém-se ao âmbito do imediato. Ao trazer a dimensão da cultura para o debate, o autor opta por restringir-se a apenas uma dimensão constitutiva da vida humana, ignorando a existência de outras, inclusive o condicionante aspecto econômico. Mais grave do que restringir a discussão acerca dos indivíduos marginalizados ao campo da cultura é não abordá-la em sentido amplo e negá-los a possibilidade de tomar parte na riqueza do acervo cultural produzido pela humanidade, do qual as elites se apropriaram. Nesse caso, oportunizar apenas a apropriação ou construção de cultura micro no interior de uma cultura maior, da qual o indivíduo se vê expropriado, pode significar apenas a validação da realidade excludente.

Com relação às situações de marginalização ou de inadaptação, Petrus (2003) defende que a educação social deve preparar o indivíduo para a participação social, para tanto, deve atuar primeiramente nas suas estruturas cognitivas e afetivas. Isto significa atuar diretamente nas condutas dos sujeitos, que por sua vez pressupõe mudanças na família, nas relações com os colegas, na escola e nas demais instituições sociais. Propõe que a educação social tem a função de "transmitir as habilidades sociais necessárias nas relações profissionais, de gerar atitudes positivas frente à cultura e às subculturas etc." (PETRUS, 2003, p. 56). 
Nesse caso, o autor desemboca também no campo do micro, do imediato, ao apostar demasiadamente no indivíduo, em sua família, em sua escola, em sua comunidade. A aposta na subjetividade é reforçada por Petrus (2003) mais adiante quando, ao tratar da atuação do educador social frente às situações de violência infantil e juvenil, afirma que a violência e a agressividade são resultados do desequilíbrio ocorrido entre os impulsos e o controle interno do indivíduo. Logo, defende que, mesmo entendendo a violência como complexo problema social, não se pode desconsiderar que atitudes de violência estão amparadas no âmbito axiológico, ou seja, nos valores internalizados pelo indivíduo.

Para explicar a violência recorre ao aspecto subjetivo e afirma que "quando nossos jovens conhecerem o que é a violência e tiverem a oportunidade de falar livremente dela em sala de aula, a violência perderá parte do atrativo pessoal e tribal que atualmente possui para alguns de nossos alunos" (PETRUS, 2003, p. 73). Assim, parece que a violência é tratada como opção consciente de livre escolha. $O$ indivíduo escolhe porque se sente atraído ou deixa de escolher quando, ao discutir sobre ela, esta perder seu caráter atrativo.

Desconsidera-se aqui que embora os valores desempenhem importante função, visto que são acionados pelo indivíduo ao tomar quaisquer atitudes, eles possuem limite, pois, como afirma Lukács (2013), o indivíduo é um complexo de complexos e os valores compõem apenas um desses complexos. Nesse caso, é preciso considerar que a violência é um dado objetivo inserido num contexto maior, cujos elementos que o desencadeiam se comunicam com a totalidade e favorecem sua permanência.

Trata-se de fenômeno que marca a vida de inúmeros jovens e crianças, deixando não apenas marcas subjetivas, mas, sequelas físicas, inclusive. Sendo fenômeno, ou seja, apenas aparência, faz-se necessário para o seu desvelamento a busca da sua essência, suas causas primeiras, os fatores que se juntam à multiplicidade do gênero humano e provocam impacto nas subjetividades dos indivíduos.

É importante, mas não suficiente discutir o que é a violência, suas causas e consequências. Imaginemos que determinado jovem aprenda na escola, ou em outros espaços como igreja e demais grupos sociais, importantes valores necessários para o desenvolvimento de um comportamento pacífico, no entanto, ele viva imerso na mais absoluta rotina de violência. Considerando que o maior violentador do indivíduo é o próprio Estado, através do seu aparato repressivo.

Essa violência, proporcionada pelo Estado, os jovens de comunidades periféricas conhecem minuciosamente de perto, pois, além da negação de serviços básicos, deparam-se cotidianamente com truculentas ações policiais. Ainda precisam enfrentar o controle de traficantes, a violência no âmbito das famílias e inúmeras outras situações de privação. Nesse sentido, a discussão sobre o que é a violência e as suas causas é necessária; trabaIhar a construção e reconstrução de vínculos afetivos pode ter um caráter humanizador; no entanto, é necessário entender que tais medidas não são suficientes. 
Fazer aposta no desenvolvimento de características subjetivas - quer dos educadores, quer dos sujeitos por eles atendidos - como condição para garantir a superação das desigualdades sociais, nos remete ao discurso liberal da meritocracia. A crença de que o desenvolvimento de qualidades pessoais justifica o lugar que o indivíduo ocupa na sociedade, como prêmio ou castigo, reforça a lógica de reprodução do sistema do capital. Este se sustenta, ao mesmo tempo, na produção de miséria e na responsabilização dos indivíduos pelos seus próprios fracassos.

Essa questão está posta de maneira tão veemente que as causas dos fracassos sociais são comumente atribuídas à insuficiente ou inadequada formação do educador social. Ao tratar das dimensões teoria e prática, Petrus (1997) defende que a educação social deve promover contínuas reflexões envolvendo essas dimensões, justamente por estar convencido de que "um número importante de fracassos que se dão no campo da educação social são devidos a uma inadequada capacitação profissional para posicionar-se frente aos problemas sociais" (PETRUS, 1997, p. 9 - tradução nossa).

Essa compreensão equivocada e tão disseminada justifica a aposta insistente na formação, na capacitação pessoal e na reflexão como elementos suficientes para a promoção de transformações substanciais na sociedade. Aposta na dimensão epistemológica que é importante, porém, não determinante. Isso traz a seguinte questão: de que maneira a reflexão e a capacitação pode promover a superação das desigualdades sociais? Como é possível admitir-se que, numa sociedade na qual apenas $1 \%$ da população mundial detém cerca de $82 \%$ de toda riqueza produzida ${ }^{6}$, a capacitação pessoal seja a condição para solucionar os problemas sociais? O que se evidencia é a incisiva negação das multideterminações sociais em benefício da adoção do discurso de culpabilização do indivíduo.

Faz-se necessário enfatizar que não negamos a importância da formação, da reflexão, e da educação como instrumento de organização de grupos sociais que pretendem lutar contra a opressão, a desigualdade e a desumanização, em prol da emancipação humana. Entretanto, trata-se apenas de meio, não pode ser o fim. O horizonte daquele que propõe lançar-se na luta por uma sociedade verdadeiramente humanizada não é e não pode ser a formação pela formação.

Por isso a importância de se reconhecer os limites desse instrumento, para não incorrermos na injustiça de atribuir aos indivíduos particulares, sejam educadores ou educandos, a responsabilidade pelos fracassos. Entender que existem determinações objetivas, condicionamentos sociais, que estão para além da ação particular do educador social. Fato que, conforme Paiva (2015), os próprios educadores sociais percebem. Mesmo valorizando e ressaltando a importância da formação, entendem que ela possui limites. Nesse sentido afirma:

6 Segundo os dados da Oxfam referentes a 2017. Informação disponível em https://g1.globo.com/economia/ noticia/super-ricos-ficam-com-82-da-riqueza-gerada-no-mundo-em-2017-diz-estudo.ghtml. Acesso em 25 de janeiro de 2018. 
O Educador Social de Rua sabe o valor que tem a formação, sabe que essa é uma necessidade pedagógica a que ele tem total direito, contudo, em sua maioria tem consciência que a formação não se constitui em uma fórmula mágica capaz de solucionar os percalços sociais nos quais estão inseridos seus educandos, a formação do educador, apesar de sua importância, possui limites e não dá conta das mazelas sociais provocadas pela desigualdade social no Brasil (PAIVA, 2015, p. 104).

Isso significa que reconhecer a importância da formação não pressupõe aposta incondicional na sua eficácia. Analisar a formação e compreender sua contribuição no processo de construção dos instrumentos de luta contra opressão requer perspectiva crítica. Exige o entendimento de que as discussões sobre formação, em evidência na sociedade contemporânea, ancoram-se nas demandas impostas pelo mercado. Demandas estas que a educação tem incorporado como parâmetros válidos e aos quais busca incansavelmente dar respostas.

Desse modo, tem ganhado espaço nos discursos educacionais conceitos deslocados da área empresarial como qualidade total, clientela e capital humano. Isto se dá porque no projeto capitalista neoliberal, predominante no Brasil desde os anos 1990, a regularização da educação, bem como da assistência, efetiva-se com base nos princípios do livre-mercado.

A formação, a profissionalização, bem como a necessidade de desenvolver competências e habilidades, são fortemente defendidas como condição para o desenvolvimento econômico da sociedade. Para atender às demandas do mercado que se complexificam cada vez mais, vende-se a ideia de que o indivíduo precisa estar constantemente em formação, atualizando-se, aperfeiçoando-se.

É daí que advém a compreensão de educação ao longo da vida e a defesa do aprender a aprender. Alega-se que não faltam vagas no mercado, o que falta é mão-de-obra qualificada, de modo que a preocupação com a formação ganha destaque nas diversas áreas. Nesse caso, o que prevalece é o discurso da preparação para o trabalho como forma de se opor ao desemprego estrutural.

Esta compreensão está alinhada com as discussões apresentadas pelos teóricos que defendem a suposta sociedade do conhecimento. Trata-se de teóricos com grande popularidade que discutem as questões sociais a partir do recorte da epistemologia, demitem a discussão política, desconsideram a base material, e se dispõem a resolver todos os problemas sociais, pretensamente, com a estruturação e o fortalecimento do conhecimento. Para tanto, propõem a interdisciplinaridade, a transdisciplinaridade, o desenvolvimento de competências e habilidade, a análise de conceitos, a aprendizagem ao longo da vida, o aprender a aprender etc., descolados da totalidade social e das questões de classe ${ }^{7}$.

7 A propósito do paradigma concernente à Sociedade do Conhecimento, como mecanismo ideológico em prol da reprodução do capital, vale a pena conferir: FRERES, Helena de Araújo. A emergência do conhecimento como paradigma produtivo no contexto da crise estrutural do capital. 2013. Tese de Doutorado. (Programa de Pós-Graduação em Educação Brasileira) - Universidade Federal do Ceará, Fortaleza. e, BARBOSA, Fabiano Geraldo. O estatuto do conhecimento em Lukács: uma análise a partir da obra Prolegômenos para uma 
Então, para não incorrermos em injustiças é necessário cautela nas apostas feitas nas subjetividades. Qualquer análise que nos propusermos a fazer acerca do ser social deverá considerar que, como afirma Lukács (2013, p. 161), "todas as ações, relações etc. - por mais simples que pareçam à primeira vista - sempre são correlações de complexos entre si [...]". Do mesmo modo, todos os atos e operações singulares, para serem compreendidos torna-se necessário considerá-los no seio do processo ao qual toma parte, ou seja, precisam ser analisados como partes integrantes do complexo ao qual pertencem.

As posições teleológicas dos indivíduos se efetivam enraizadas na objetividade do mundo e trazem consigo as marcas da história, da totalidade genérico-social. As escolhas efetivadas pelo gênero humano que altera a série de cadeias causais e retroagem sobre o indivíduo exercem influência nas escolhas e nos atos singulares. Isso porque é a totalidade que põe as possibilidades e a liberdade do indivíduo está em fazer escolhas frente às possibilidades apresentadas.

\section{CONSIDERAÇÕES FINAIS}

As mudanças não podem ser implementadas apenas no âmbito da singularidade, as transformações precisam abarcar elementos da singularidade, da particularidade e da universalidade, pois, como afirma Lukács (2010, p. 78), o "processo de reprodução dos organismos singulares transcorre no quadro de sua respectiva generalidade". Ao mesmo tempo é preciso compreender que a universalidade do gênero humano é uma expressão do ser, ou seja, da singularidade.

Na mesma direção aponta Leontiev (1978), em consonância com Marx, quando afirma que ao nos referirmos à subjetividade do indivíduo é preciso entendê-la como resultado das produções históricas e culturais, uma vez que é limitada pelos elementos objetivos da sua época e da sua sociedade. Isso decorre do fato, anteriormente discutido, de que o indivíduo constitui seus modos de ser num movimento dialético no qual, ao mesmo tempo em que intervém na natureza para retirar dela meios de subsistência, transforma o mundo e é por ele transformado. Portanto, é na relação entre subjetividade e objetividade que o indivíduo entra em interação com a produção tanto material quanto fenomênica e se faz humano. Essa premissa não pode jamais ser desconsiderada.

Nesse processo, a educação em sua concepção ampla cumpre o propósito de garantir a continuidade dos elementos da totalidade social, nos indivíduos singulares, visando à conservação do gênero, uma vez que o ser existe ao mesmo tempo como generidade e singularidade. Logo, a educação aponta para um projeto de sociedade que já está posto na sua ação interventiva ao educar o indivíduo. Quando através do ato educativo cada exemplar singular é preparado para compor a universalidade do gênero, as teleologias 
postas nessa ação apontam para objetivação de um modelo de sociabilidade previamente idealizado.

Desse modo, precisamos nos questionar sobre as reais possibilidades que se apresentam a esses sujeitos atendidos pela educação social, ditos em situação de risco e vulnerabilidade. Considerando que o indivíduo se põe no mundo no movimento que articula necessidades e possibilidades, é importante sempre nos questionarmos: quais as necessidades desses sujeitos e quais as possibilidades reais de satisfação das suas necessidades humanas? Quais os problemas que os afligem e quais os limites e contradições da atuação do educador social?

Quando determinada área do conhecimento, conforme Lukács (2012), nega-se a fazer perguntas ontológicas, não se interessa em conhecer o ser existente em si, indo à gênese do complexo de problemas, cai na imediaticidade formal e explica os problemas sem conhecer o verdadeiro ser-em-si dos fatos. Isso pode levar ao mais puro processo de manipulação da realidade e constitui-se como o falso socialmente necessário, visto que apenas contribui para manutenção dos privilégios de classe através da perpetuação dessa sociedade excludente regida pela lógica do capital, na qual, segundo Mészáros (2005), tudo se vende, tudo se compra, tudo tem preço.

Portanto, uma educação que se coloca a serviço dos excluídos necessita minimamente atacar a lógica perversa que rege essa sociedade excludente e ter como horizonte uma sociedade verdadeiramente humanizada. Pois, somente quando profundas transformações forem provocadas na estrutura da sociedade, que se sustenta no domínio do capital sobre o trabalho, será possível a educação cumprir sua função emancipadora. 


\section{REFERÊNCIAS}

AMORIM, Maria Gorete; SANTOS, Maria Escolástica de Moura. O caráter de classe da reforma do ensino médio. Arma da crítica, ano 6, n. 7. Dez. 2016.

BEZERRA, Maria do Socorro Sales. AABB Comunidade: projeto político pedagógico. In: RAMOS, Marcos Fadanelli; ROMAN, Artur. Educadores sociais: a importância da formação na implementação de tecnologias sociais. Brasília: Fundação Banco do Brasil, 2011. p. 115-122.

BORÓN, Atílio. A sociedade civil depois do dilúvio neoliberal. In: Pós-neoliberalismo: as políticas sociais e o Estado democrático. 8 ed. Rio de Janeiro: Paz e Terra, 1995. p. 63-118.

BRALICH, Jorge. ¿Es posible "otra" pedagogia social? Revista Pedagógica, $n^{\circ} 2$, abril 2012. p. 71-86.

BRASIL. Lei de Diretrizes e Bases da Educação Nacional. Lei n. 9.394, de 20 de dezembro de 1996. Disponível em: http://www.planalto.gov.br/ccivil 03/leis/L9394.htm. Acesso em 18 de julho de 2016.

CUNHA, Roberta de Castro. Os sentidos da educação social para jovens educadores sociais: ressignificação de vida ou perpetuação do existente? 2012. 128 f. Dissertação (Mestrado em Políticas Públicas) - Centro de Humanidades e Estudos Sociais Aplicados. Universidade Estadual do Ceará, Fortaleza.

FERNANDES, Luis. Neoliberalismo e reestruturação capitalista. In: Pós-neoliberalismo: as políticas sociais e o Estado democrático. 8 ed. Rio de Janeiro: Paz e Terra, 1995. p. 54-61.

GONZALEZ, Mathias. Combate à violência na família, escola e comunidade. In: RAMOS, Marcos Fadanelli; ROMAN, Artur. Educadores sociais: a importância da formação na implementação de tecnologias sociais. Brasília: Fundação Banco do Brasil, 2011. p.123-128.

LEONTIEV, Alexis. O desenvolvimento do psiquismo. Lisboa: Horizonte Universitário, 1978.

LUKÁCS, György. Prolegômenos para uma ontologia do ser social: questões de princípios para uma ontologia hoje tornada possível. São Paulo: Boitempo, 2010.

LUKÁCS, György. Neopositivismo e existencialismo. In: cial. Livro I. 1 ed. São Paulo: Boitempo, 2012. p. 46-127.

Para uma ontologia do ser so-

LUKÁCS, György. Para uma ontologia do ser social. Livro II. 1 ed. São Paulo: Boitempo, 2013.

MARX, Karl. Processo de trabalho e processo de produzir mais-valia. In: O capital: crítica da economia política. Livro I. 24 ed. Rio de Janeiro: Civilização Brasileira, 2006. p. 209-231.

MARX, Karl. O 18 de Brumário de Luís Bonaparte. São Paulo: Boitempo, 2011.

MARX. Karl; ENGELS, Friedrich. Feuerbach e história: rascunhos e anotações. In: A ideologia alemã: crítica da mais recente filosofia alemã em seus representantes Feuerbach, B. Bauer e Stirner, e do socialismo alemão em seus diferentes profetas. São Paulo: Boitempo, 2007. 
MÉSZÁROS, Istiván. A educação para além do capital. São Paulo: Boitempo, 2005.

MÉSZÁROS, Istiván. A ordem da reprodução sociometabólica do capital. In: Para além do capital: rumo a uma teoria da transição. 1. ed revista. São Paulo: Boitempo, 2011. p. 94-132.

NUÑES, Violeta. Participación y educación social. In: SOUSA NETO, João Clemente; SILVA, Roberto da; MOURA, Rogério (Org.). Pedagogia Social. São Paulo: Expressão e Arte Editora, 2009. p. 241-256.

PAIVA. Jaciara Silva de. Caminhos do educador social no Brasil. Jundiaí: Paco Editorial, 2015.

PETRUS, Antoni. Concepto de educación social. In: (Org.). Pedagogía social. Barcelona: Ariel Educación, 1997. p. 9-39.

PETRUS, Antoni. Novos âmbitos em educação social. In: ROMANS, Mercès; PETRUS, Antoni; TRILLA, Jaume. Profissão: educador social. Porto Alegre: Artmed, 2003. p.51-64.

SILVA, Gerson Heidrich. A construção de identidade do educador social na sua prática cotidiana: a pluralidade de um sujeito singular. 2008. 239 f. Dissertação (Mestrado em Educação) - Faculdade de Educação. Universidade de São Paulo-USP. São Paulo, 2008. 